Chronic Obstructive Pulmonary Diseases:

Journal of the COPD Foundation

COPD

FOUNDATION

\title{
Review
}

\section{Why is Disease Penetration So Variable? Role of Genetic Modifiers of Lung Function in Alpha-1 Antitrypsin Deficiency}

\author{
Brian D. Hobbs, MD, $\mathrm{MMSc}^{1}$ Michael H. Cho, MD, MPH ${ }^{1}$
}

\begin{abstract}
Individuals with alpha-1 antitrypsin deficiency (AATD) have marked heterogeneity in lung function, suspected to be related to a combination of both environmental (e.g., cigarette smoking) and genetic factors. Lung function is heritable in the general population and in persons with severe AATD. Several genetic modifiers of lung function in persons with AATD have been described; however, replication is lacking. A genome-wide association study (GWAS) of lung function in persons with AATD has yet to be performed and may inform whether genetic determinants of lung function are overlapping in persons with AATD and in the general population. As GWASs require large sample sizes for adequate power, genetic risk scores offer an alternate approach to assess the overlap of genetic determinants of lung function in the general population in persons with AATD. Where GWASs are limited to common genetic variant discovery, whole genome sequencing (for rare variant discovery) and integrative genomic studies (examining the influence of genetic variants on gene, protein, and metabolite levels) offer potential for an expanded discovery of genetic modifiers of lung function in AATD. In the following review we examine past descriptions of genetic modifiers of lung function in AATD and describe a path forward to further investigate and define the likely genetic modifiers of lung function in AATD.
\end{abstract}

\begin{abstract}
Abbreviations: alpha-1 antitrypsin deficiency, AATD; genome-wide association study, GWAS; forced expiratory volume in 1 second, FEV1; chronic obstructive pulmonary disease, COPD; forced vital capacity, FVC; single nucleotide polymorphisms, SNPs; endothelial nitric oxide synthase gene, NOS 3; glutathione S-transferase pi 1 gene, GSTP 1; interleukin-10 gene, IL 10; tumor necrosis factor alpha, TNFa

Funding Support: BDH is supported by NIH K08 HL136928, R01 HL089856, and the Parker B. Francis Research Opportunity Award. MHC is supported by NIH R01 HL135142 and R01 HL089856.

Date of Acceptance: January 28, 2020

Citation: Hobbs BD, Cho MH. Why is disease penetration so variable? Role of genetic modifiers of lung function in alpha-1 antitrypsin deficiency. Chronic Obstr Pulm Dis. 2020;7(3):214-223. doi: https://doi.org/10.15326/jcopdf.7.3.2019.0159
\end{abstract}

1 Channing Division of Network Medicine and Division of Pulmonary and Critical Care Medicine, Brigham and Women's Hospital, Boston, Massachusetts

\section{Address correspondence to:}

Brian D Hobbs, MD, MMSc

phone: 617-525-2140

email: brian.hobbs@channing.harvard.edu

\section{Keywords:}

alpha-1 antitrypsin deficiency; lung function; chronic obstructive pulmonary disease; COPD; genetic modifiers; heterogeneity

\section{Introduction}

Severe alpha- 1 antitrypsin deficiency (AATD) results in dramatically lower levels of protein, but the variability of clinical presentation, particularly with regard to lung function, is a well-known phenomenon. In 1989, Silverman et al studied lung function levels in 52 type $\mathrm{Pi} Z$ ( $\mathrm{Pi}^{*} \mathrm{ZZ}$ or $\left.\mathrm{PiZ}{ }^{*} \mathrm{Null}\right)$ individuals with severe AATD, and showed that the majority of individuals not specifically ascertained based on low lung function levels had a forced expiratory volume in 1 second $\left(\mathrm{FEV}_{1}\right)$ greater than $65 \%$ of predicted. ${ }^{1}$ A 2017 mortality study by Tanash et al reported that neversmoking PiZZ individuals identified by population or family screening (i.e., not ascertained on respiratory or hepatic symptoms or disease) had a similar survival compared to never-smokers in the general Swedish 
population. ${ }^{2}$ These studies highlighted not only the variability in lung function levels of persons with severe AATD, but also highlighted the impact of ascertainment bias in the interpretation of studies involving persons with severe AATD.

Cigarette smoking history significantly impacts lung function variability as well as mortality in AATD. Castaldi et al reported a non-linear relation between pack years of smoking and $\mathrm{FEV}_{1}$ with a steep decline in $\mathrm{FEV}_{1}$ for $0-20$ pack years of smoking and a more gradual decline in $\mathrm{FEV}_{1}$ for $20+$ pack years of smoking (Figure 1). ${ }^{3}$ The most important predictors of $\mathrm{FEV}_{1} \%$ of predicted were age, age-by-pack-years interaction, sex, pack years of smoking (0-20 only), index case status (ascertainment adjustment), and childhood pneumonia. ${ }^{3}$ Abnormal lung function alone is likely insensitive to the effect of smoking; ever- and never-smokers with $\mathrm{Pi}^{*} \mathrm{ZZ}$ AATD have variability in symptoms. This was demonstrated in a study of 107 PiZ 30-year-old individuals in Sweden where PiZ ever-smokers reported significantly more phlegm, wheezing, and shortness of breath compared to PiZ never-smokers. ${ }^{4}$ Thus, cigarette smoking history and ascertainment bias are important contributors to the reported variability of lung function (and other clinical features) in severe AATD. However, smoking history and ascertainment, even when modeled with other important contributors to reduced lung function, ${ }^{3}$ do not account for the totality of lung function variability in AATD.

\section{Heritability of Lung Function in Alpha-1 Antitrypsin Deficiency}

In persons without AATD, genetic factors account for a proportion of the observed variability in the development of chronic obstructive pulmonary disease (COPD) and in the population variation in spirometry values including $F E V_{1}$, forced vital capacity (FVC), and ratio of $\mathrm{FEV}_{1} / \mathrm{FVC}$. The contribution of genetic variation to the variability in clinical features (such as spirometry levels) or the development of disease (such as COPD) is heritability. Heritability estimates for COPD range from 38\%-63\% with the heritability of $\mathrm{FEV}_{1}$ and $\mathrm{FEV}_{1} / \mathrm{FVC}$ ratio ranging from $31 \%$ $50 \%$ and $45 \%-66 \%$, respectively. ${ }^{5-11}$ In cystic fibrosis, another monogenic respiratory disease with a substantial impact on lung function, studies have found substantial heritability of lung function. ${ }^{12}$ In

\section{Figure 1. Relation Between Forced Expiratory Volume in 1 Second and Pack Years of Cigarette Smoking in $231 \mathrm{Pi}^{*} \mathrm{ZZ}$ Smokers ${ }^{\mathrm{a}}$}

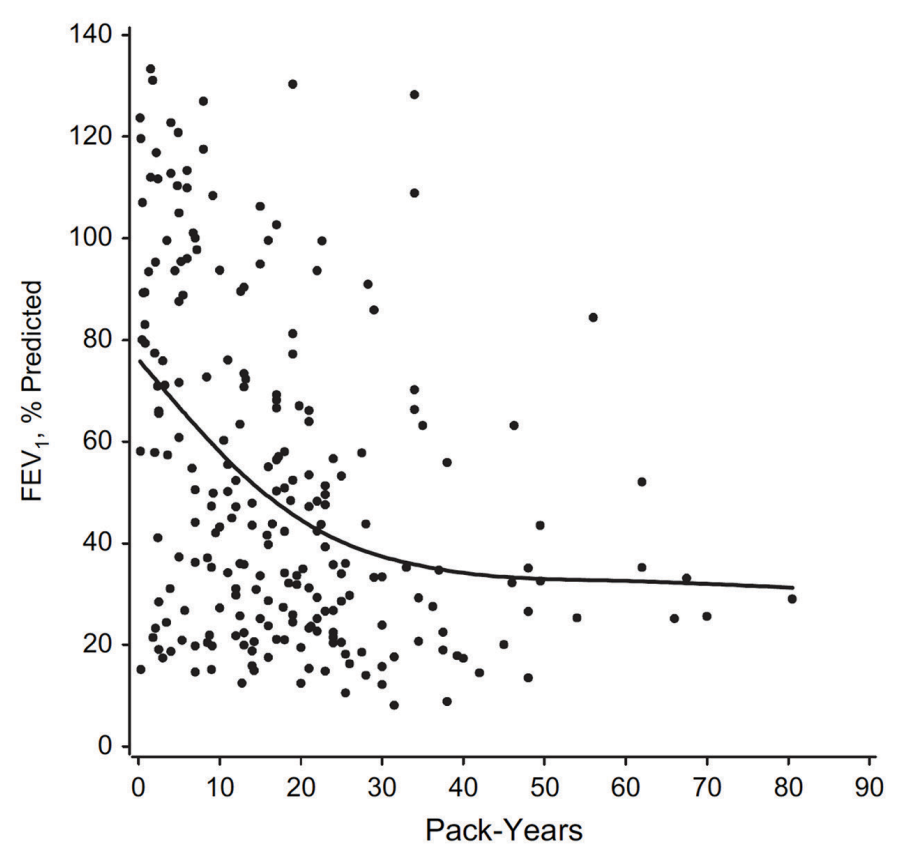

afrom the AAT Genetic Modifier Study, 2002-2005

The figure shows a scatterplot with a smoothing curve demonstrating the trend in $\mathrm{FEV}_{1}$ percentage predicted with increasing pack years of tobacco exposure, with a linear trend from 0 pack years to 19.9 pack years. Nonsmoking subjects with the protease inhibitor 22 genotype were not included.

AAT $=$ alpha-1 antitrypsin deficiency

Reprinted with permission from Oxford Academic and the Johns Hopkins Bloomberg School of Public Health $\left({ }^{3}\right.$ Castaldi PJ, DeMeo DL, Kent DM, et al. Development of predictive models for airflow obstruction in alpha-1 antitrypsin deficiency. Am J Epidemiol. 2009;170(8):1005-1013.

doi: https://doi.org/10.1093/aje/kwp216)

persons with severe AATD, genetic variation is also a likely explanation for the observed variability of the development of impaired lung function. In a familial study of PiZZ AATD individuals in 1990, Silverman et al reported a trend toward reduced $F E V_{1}$ in the PiMZ parents of AATD individuals with impaired FEV 1 ( $<65 \%$ of predicted). ${ }^{13}$ The familial influence on reduced lung function was later investigated in the AAT Genetic Modifiers Study, a multicenter family-based cohort study of 378 individuals with severe AATD confirmed to be homozygous for the SERPINA 1 $\mathrm{Z}$ allele (rs28929474). ${ }^{14}$ In this study, heritability 
estimates for post-bronchodilator $\mathrm{FEV}_{1}$ and $\mathrm{FEV}_{1} /$ FVC ratio were $\sim 19 \%$ and $\sim 26 \%$, respectively, when adjusting for index case ascertainment bias and smoking history. ${ }^{15}$ Thus, convincing evidence exists for the heritability of lung function levels in the general population and in persons with severe AATD.

\section{Candidate Gene Studies}

The candidate gene approach for finding genetic modifiers of disease starts with biologically plausible (i.e., with known function and potentially diseasecausing) genes and associates genetic variation (usually single nucleotide polymorphisms [SNPs]) in those genes with the presence or absence of a disease (such as COPD) or with levels of a clinical feature (such as lung function). ${ }^{16,17} \mathrm{~A}$ positive genetic association analysis is typically taken as evidence for an association of the candidate gene with the disease or trait of interest. Several candidate gene studies, detailed below, have been performed to attempt to explain lung function variability in severe AATD (Table 1).

\section{Endothelial Nitric Oxide Synthase}

The endothelial nitric oxide synthase (NOS3) gene produces one of the enzymes responsible for the nitric oxide synthesis from L-arginine, ${ }^{18}$ and was chosen as a candidate gene in AATD because of nitric oxide's role in the regulation of pulmonary vascular and airway tone. ${ }^{19}$ In a study of 345 persons with AATD compared to 93 controls, the authors focused their association analyses on 2 common genetic variants in NOS3, $774 \mathrm{C} / \mathrm{T}$ and $894 \mathrm{G} / \mathrm{T}$, which are in strong linkage disequilibrium (i.e., the 2 genetic variants are highly correlated due to co-inheritance in a block, or haplotype, of genetic material). The authors reported an association between 2 NOS 3 variants $(774 \mathrm{C} / \mathrm{T}$ and $894 \mathrm{G} / \mathrm{T})$ and severe lung disease $\left(\mathrm{FEV}_{1}<35 \%\right.$ of predicted) in persons with AATD, noting that the allele frequencies of these 2 variants in persons with AATD and less severe lung disease $\left(\mathrm{FEV}_{1}>35 \%\right.$ of predicted) were similar to the observed allele frequencies in a control population. ${ }^{20}$ Thus, the authors postulated a modulatory effect of NOS 3 on severe destructive lung disease.

\section{Glutathione S-Transferase Pi 1}

The glutathione S-transferase pi 1 (GSTP 1) gene produces an enzyme important to cellular protection from cytotoxic agents through detoxification of electrophilic substances (such as exist in cigarette smoke) and is expressed in the lungs. ${ }^{21}$ A specific genetic variant (Ile105Val a.k.a. rs1695) in GSTP1 had been previously associated with COPD. ${ }^{22}$ With a possible functional role in cigarette smoke susceptibility and with prior association with COPD, Rodriguez et al sought to investigate an association between the frequency of the Ile105Val (rs1695) GSTP 1 polymorphism and AATD. ${ }^{23}$ The authors reported that the allele frequency of the GSTP 1 variant rs 1695 was similar in persons with COPD and in the general population (controls) though was significantly increased in persons with AATD; further, rs 1695 was associated with reduced $\mathrm{FEV}_{1}$ in current and former smokers with AATD, but not in neversmokers with AATD, and not in persons with nonAATD COPD. ${ }^{23}$ Therefore, the authors concluded that GSTP 1 modulated lung disease specifically in AATD current and former smokers.

\section{Interleukin-10 Gene}

In 2008, DeMeo et al evaluated 75 SNPs in 10 candidate genes including IL 10, TNF, GSTP 1, NOS 1, NOS3, SERPINA3, SERPINE2, SFTPB, TGFB 1, and EPHX1 (chosen for prior reported associations with either asthma and/or COPD) for association with either $F E V_{1}$ and $F E V_{1} / F V C$ ratio in the AAT Genetic Modifiers family-based study. ${ }^{24}$ Correlated SNPs (rs1800871 and rs1518110) in IL 10 were significantly associated with $\mathrm{FEV}_{1}, \mathrm{FEV}_{1} / \mathrm{FVC}$ ratio, and moderate-to-severe COPD. The IL 10 SNPs were the only SNPs showing significant associations with both quantitative spirometry and binary COPD status; further, the rs $1800871 \mathrm{FEV}_{1}$ and $\mathrm{FVC}_{1}$ / FVC ratio association $p$ values remained significant after adjustment for multiple testing (either 10 candidate genes or 75 SNPs). The study by DeMeo and colleagues was additionally notable in the lack of replication of the previously reported case-control study associations of SNPs in NOS3 and GSTP1 with lung function levels and COPD in persons with AATD.

\section{Tumor Necrosis Factor}

Tumor necrosis factor alpha (TNF, formerly known as TNFa) is an inflammatory cytokine shown to be elevated in sputum, bronchial biopsies and 


\section{Table 1. Summary of Previously Reported Genetic Modifiers of Lung Disease in Alpha-1 Antitrypsin Deficiency}

\begin{tabular}{|c|c|c|c|c|c|}
\hline Gene(s) & $\begin{array}{l}\text { Significant SNPs } \\
\text { (as reported - rsid) }\end{array}$ & Association Phenotypes & Sample Size & Replication? & Reference \\
\hline NOS3 & $\begin{array}{l}774 \mathrm{C} / \mathrm{T}-\mathrm{rs} 1549758 \\
894 \mathrm{G} / \mathrm{T}-\mathrm{rs} 1799983\end{array}$ & $\mathrm{FEV}_{1}<35 \%$ Predicted & $\begin{array}{r}345 \text { AATD } \\
93 \text { Controls }\end{array}$ & No & $\begin{array}{r}\text { Novoradovsky } \\
\text { et al }{ }^{20}\end{array}$ \\
\hline GSTP1 & p.Ile105Val - rs1695 & $\begin{array}{r}\text { AATD vs. COPD vs. Control } \\
\text { FEV }_{1} \% \text { Predicted }\end{array}$ & $\begin{array}{r}69 \text { AATD } \\
98 \text { COPD } \\
198 \text { Controls }\end{array}$ & No & $\begin{array}{r}\text { Rodriguez } \\
{\text { et } \mathrm{al}^{23}}^{23}\end{array}$ \\
\hline IL10 & rs1800871, rs1518110 & $\mathrm{FEV}_{1}, \mathrm{FEV}_{1} / \mathrm{FVC}, \mathrm{COPD}$ & $\begin{array}{r}378 \mathrm{Pi}^{\star} \text { ZZ Persons } \\
\text { (family study) }\end{array}$ & No & $\begin{array}{l}\text { DeMeo } \\
\text { et al24 }\end{array}$ \\
\hline \multirow[t]{2}{*}{ TNF } & rs1800610, rs769178 & $\mathrm{FEV}_{1}, \mathrm{FEV}_{1} / \mathrm{FVC}$ & $\begin{array}{r}378 \text { Pi`ZZ Persons } \\
\text { (family study) }\end{array}$ & No & $\begin{array}{r}\text { DeMeo } \\
\text { et al }{ }^{24}\end{array}$ \\
\hline & rs361525 & Chronic Bronchitis & $\begin{array}{r}424 \text { PiZZ Persons } \\
\text { (unrelated) }\end{array}$ & No & Wood et $\mathrm{al}^{26}$ \\
\hline $\begin{array}{l}\text { IREB2, } \\
\text { HYKK, } \\
\text { CHRNA3 }\end{array}$ & $\begin{array}{r}\mathrm{rs} 2568494, \mathrm{rs} 8034191 \\
\mathrm{rs} 1051730\end{array}$ & pre-BD FEV ${ }_{1} \%$ Predicted & $\begin{array}{r}\text { Discovery: } \\
378 \mathrm{Pi}^{\star} \mathrm{ZZ} \text { Persons } \\
\text { (family study) }\end{array}$ & $\begin{array}{l}\text { No replication } \\
\text { of lung function } \\
\text { associations. }\end{array}$ & Kim et $\mathrm{al}^{40}$ \\
\hline $\begin{array}{l}\text { IREB2, } \\
\text { CHRNA3 }\end{array}$ & rs2568494, rs 1051730 & $\begin{array}{r}\text { post-BD FEV }{ }_{1} \% \text { Predicted } \\
\text { pre-BD FEV } 1 / F V C\end{array}$ & $\begin{array}{r}\text { Attempted Replication: } \\
458 \mathrm{Pi}^{*} \mathrm{ZZ} \text { Persons } \\
\text { (unrelated) }\end{array}$ & $\begin{array}{l}\text { Gender and } \\
\text { smoking } \\
\text { interactions } \\
\text { with genotype } \\
\text { were replicated. }\end{array}$ & \\
\hline
\end{tabular}

$\mathrm{SNP}=$ single nucleotide polymorphisms; $\mathrm{FEV}_{1}=$ forced expiratory volume in 1 second; $\mathrm{AATD}=$ alpha- 1 antitrypsin deficiency; $\mathrm{COPD}=$ chronic obstructive pulmonary disease; $\mathrm{FEV} 1 / \mathrm{FVC}=$ ratio of $\mathrm{FEV}_{1}$ to forced vital capacity; $\mathrm{BD}=$ bronchodilator

circulation of COPD patients and was thus an attractive gene for COPD susceptibility. That said, many studies failed to replicate the initial report of TNF genetic variant associations with COPD and COPD-related phenotypes. ${ }^{25}$ Possibly owing to the increased role of inflammation in AATD compared to usual COPD, both DeMeo et $\mathrm{l}^{24}$ and Wood et $\mathrm{al}^{26}$ investigated TNF variants as potential genetic modifiers of AATD phenotypes. DeMeo and colleagues evaluated 5 TNF SNPs (rs1800629, rs361525, rs 1800610, rs3091257, and rs769178) in the AAT Genetic Modifiers study and reported SNP associations with pre-bronchodilator FEV 1 (rs1800610 and rs769178), $\mathrm{FEV}_{1} / \mathrm{FVC}$ ratio (rs3091257 and rs769178), and moderate-tosevere COPD (rs769178). Investigating 4 TNF SNPs (rs1800629, rs361525, rs1799964, and rs3093662), Wood and colleagues reported an association of TNF promoter SNP rs361525 with chronic bronchitis, but found no significant associations of TNF variants with emphysema, bronchiectasis, lung function, or $\mathrm{FEV}_{1}$ decline. $^{26}$
Notably, the TNF variant rs361525 is in linkage equilibrium (not correlated) with any of the significant TNF variant (rs1800610, rs769178, and rs3091257) associations with lung function levels reported by DeMeo et al. ${ }^{24}$ In summary, in persons with PiZZ AATD, DeMeo et al reported TNF variant associations with lung function and Wood et al reported a TNF variant association with chronic bronchitis (but not lung function). The 2 sets of TNF variants were not in linkage disequilibrium (i.e., they were not correlated) with each other (Figure 2) and thus these results represent potentially separate genetic signals.

\section{The Genome-wide Association Study Era}

Though the candidate gene association studies above are based on biologically plausible processes, the results of the above candidate gene studies should be scrutinized on several points. First, none of the above results have been replicated, though replication 
Figure 2. Correlation Structure of Genetic Variants Near TNF Previously Reported to Be Associated with Lung Function Levels in Persons with Alpha-1 Antitrypsin Deficiency

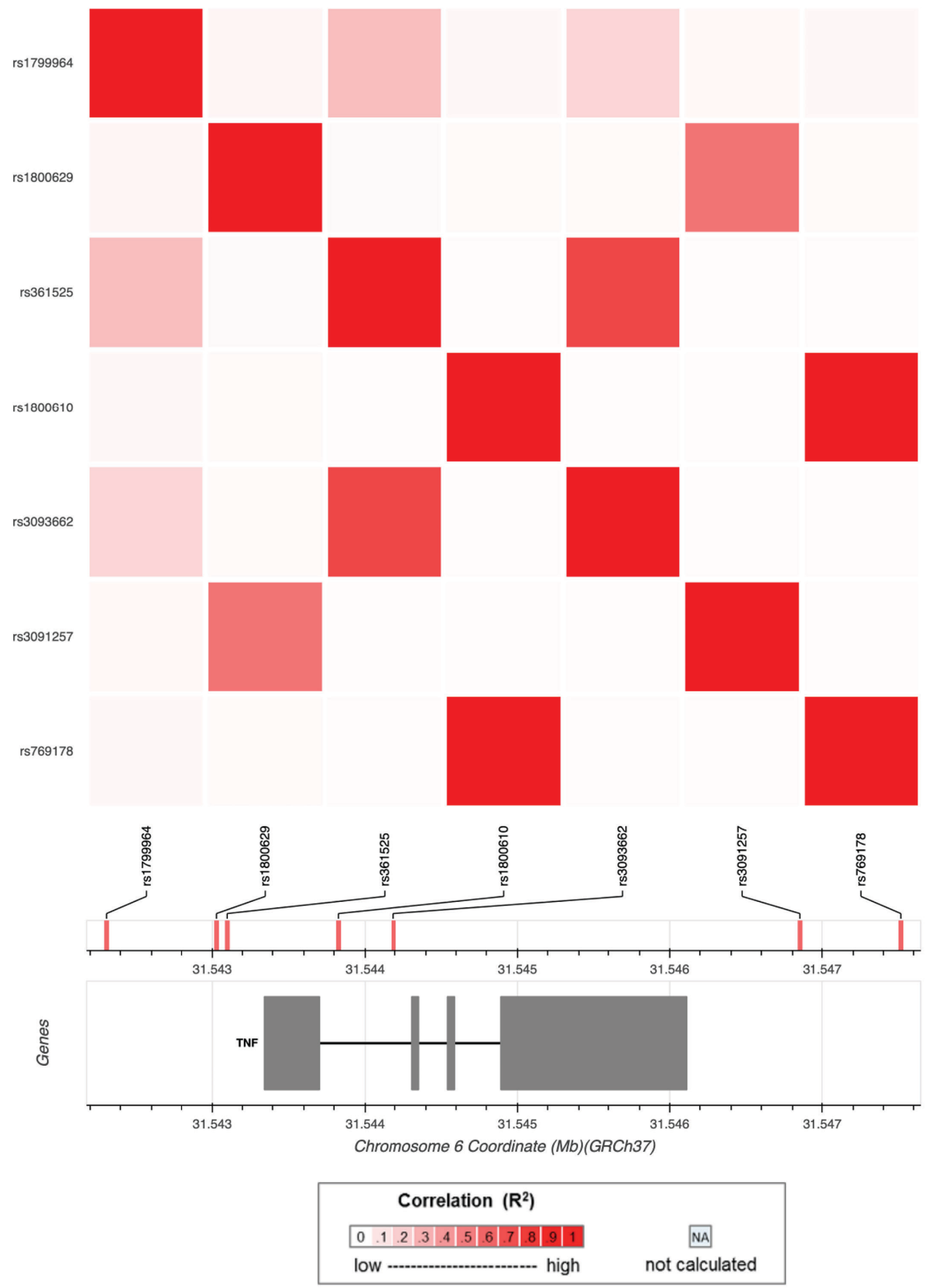


was attempted (and failed) for the association of NOS 3 and GSTP 1 with lung function in AATD. The reported associations with IL 10 and TNF have yet to be subjected to replication.

One potential reason for failed replication of genetic modifiers of AATD is that many of the candidate gene studies were not controlled for potential confounding due to smoking history and few were controlled for confounding due to ancestry-related allele frequency differences known as "population stratification."27-29 Another major limitation is that the genetic variants often do not affect the nearest gene, as has been shown in the complex disease schizophrenia. ${ }^{30}$ Thus, several of the variants tested may actually not affect the gene of interest. Other limitations include lack of power and inadequate correction for multiple testing burden. Thus, as candidate gene studies ${ }^{31-33}$ have been described to have replication rates of approximately $1.2 \%$ and false positive to false negative ratios potentially exceeding $100: 1$, it is likely that the candidate gene studies of genetic modifiers of lung function in AATD represent false positive associations that will not be replicated.

One possible solution to address the poor replicability of candidate gene studies is to perform a genome-wide association study (GWAS) of lung function in AATD. GWASs associate genome-wide, common (greater than 5\% population frequency) genetic variants with a disease (such as COPD) or a trait (such as lung function levels). In addition to more stringent techniques to adjust for population substructure and multiple testing, one of the major findings of a GWAS is that most of the findings are in novel genes; that is, not previously identified by the literature. These qualities have led many modern GWASs, with strict adjustment of $p$ values (often to $p<$ $5 \times 10^{-8}$ ) to avoid false positive associations as well as the practice of replication in an independent sample to avoid unmeasured biases, to result in much more robust replication of putative genotype-phenotype associations. ${ }^{34,35}$ Specific to obstructive lung disease, recent GWASs have provided important insights into the genetic susceptibility to reduced lung function and COPD. ${ }^{36-39}$

Given the strength of these replicated GWAS findings, one question has been to determine whether these variants have similar impact in severe AATD. One of the first and still strongest associations with COPD is at the 15q25 locus. In 2012, Kim and colleagues examined genetic variants in the $15 \mathrm{q} 25$ region for possible genetic modifiers of lung function in AATD. ${ }^{40}$ This was a different type of candidate gene study compared to the aforementioned studies in 2 aspects: (1) the chromosome $15 q 25$ region was chosen based on evidence from a GWAS of COPD, ${ }^{41}$ and (2) the study design included test (AAT Genetic Modifiers Study [n=378]) and replication (UK AATD National Registry [n=458]) cohorts. Evaluating 9 total SNPs in the chromosome 15q25 locus, Kim et al reported 2 nominal (i.e., $p$ values were not significant when adjusting for multiple comparisons) SNP associations (rs2568494 in IREB2 and rs 1051730 in CHRNA3) with both post-bronchodilator FEV 1 and pre-bronchodilator $\mathrm{FEV}_{1} / \mathrm{FVC}$ ratio in the AAT Genetic Modifiers Study. These lung function associations were not replicated in the UK National Registry dataset, though the IREB2 SNP (rs2568494) was associated with emphysema (males only) and exhibited an SNP by smoking interaction. ${ }^{40}$ Thus, despite the use of GWAS evidence to inform the choice of a candidate genetic region, this study reinforced the difficulty in replication of genetic association analysis results in the search for genetic modifiers of lung function in AATD.

Whether these findings are because the 15q25 locus has a weaker effect size or truly no effect is still not clear. Sample size is critical for adequate power in genetic association analysis, particularly for GWAS. ${ }^{42}$ The discovery of genetic loci related to lung function in AATD may be limited owing to the small sample size of AATD cohorts with genetic data. A sufficiently large GWAS in alpha-1 deficiency has yet to be performed. The utility of GWASs in the discovery of genetic modifiers of monogenic lung disease (such as AATD) has been demonstrated in cystic fibrosis. ${ }^{43,44}$ As the genomics field advances, several additional avenues of exploration are emerging. GWASs typically interrogate only common variants, and the key genetic modifiers of alpha-1 may be rare or may have been poorly captured on existing genotyping platforms. Whole exome and/ or genome sequencing offers opportunities to uncover genetic modifiers missed by a GWAS. A recent exome sequencing study in $9 \mathrm{Pi}^{*} \mathrm{ZZ}$ individuals offers a first look at the potential of sequencing technology to contribute to our understanding of genetic modifiers of lung function in AATD. ${ }^{45}$ However, the small sample size (including only 2 former smokers) and lack of replication make the results difficult to interpret at 
this time. Whole genome sequencing data in large populations are increasingly available through efforts such as the Trans-Omics for Precision Medicine program through the National Heart, Lung, and Blood Institute at the National Institutes of Health and have the potential to enhance rare variant discovery for complex respiratory traits and diseases. Integrative genomic methods leverage genetic data against gene expression, methylation, proteomic, and metabolomics data, and may increase the power (over GWAS alone) to identify relevant genes and/or pathways. ${ }^{46-49}$

Another path forward to answer the question about the population-derived GWAS loci relevance to lung function in AATD is via aggregate genetic risk scores. Genetic risk scores present a betterpowered opportunity to evaluate if known genetic loci contributing to reduced lung function and COPD in the general population are relevant to persons with AATD. Genetic risk scores also may be more powerful ways to assess for the presence of gene environment interaction. ${ }^{50}$ Genetic risk scores are aggregate measures of the genetic risk to a particular trait or disease and are generated for an individual by counting the number of risk alleles (i.e., 0,1 , or 2 ) a person carries. These genetic risk scores can then be evaluated for association with a trait or disease.

For example, a recent GWAS of spirometry levels in the United Kingdom Biobank identified 279 genetic loci associated with reduced lung function and aggregated these variants into a genetic risk score demonstrating association with reduced $\mathrm{FEV}_{1} /$ FVC ratio and showed that each standard deviation increase in the genetic risk score was associated with a 1.55 (95\% confidence interval 1.48-1.62) increased odds for COPD and a P-value of $2.87 \mathrm{e}-75.39 \mathrm{~A}$ genetic risk score utilizing a subset of the abovementioned 279 variants showed an association with lung function, emphysema, and small airways disease on quantitative computed tomography imaging. ${ }^{51}$ An analysis of a population-derived genetic risk score, such as the 279-variant genetic risk score, would allow researchers to establish if genetic modifiers of lung function in AATD are overlapping with the genetic risk for lower lung function in the general population or if the genetic risk for lower lung function in AATD is distinct. Answering this question is critical to guiding future research into the heterogeneity of lung function levels in severe AATD. Evidence of differences in the genetic susceptibility for lower lung function in the general population compared to AATD should prompt ongoing investigations, such as large-scale GWASs, into the distinct genetic modifiers of lung function in AATD.

\section{Conclusion}

The heterogeneity of lung function in persons with AATD is partially attributable to genetics. Discovery of genetic modifiers of lung disease may allow for a greater understanding of the underdiagnosis and variable clinical presentation of persons with AATD. Although previous studies have attempted to ascribe genetic variants in a variety of candidate genes to lung function traits in AATD, replication of these findings has been problematic. GWASs to discover novel genetic susceptibility loci as well as genetic risk scores of known COPD and lung function genetic loci may help to establish whether the genetic modifiers of lung function in AATD are overlapping or distinct from the genetic modifiers of lung function in the general population. Sequencing-based studies and integrative genomic studies offer additional exciting opportunities for future descriptions of the biologic underpinnings of lung function heterogeneity in AATD.

\section{Declaration of Interest}

$\mathrm{BDH}$ has nothing to declare. MHC has received grant support from Bayer and GSK, and speaking and consulting fees from AstraZeneca and Illumina. 


\section{References}

1. Silverman EK, Pierce JA, Province MA, Rao DC, Campbell EJ. Variability of pulmonary function in alpha-1 antitrypsin deficiency: clinical correlates. Ann Intern Med. 1989;111(12):982991. doi: https://doi.org/10.7326/0003-4819-111-12-982

2. Tanash HA, Ekstrom M, Ronmark E, Lindberg A, Piitulainen E. Survival in individuals with severe alpha-1 antitrypsin deficiency (PiZZ) in comparison to a general population with known smoking habits. Eur Respir J. 2017;50(3):1700198. doi: https://doi.org/10.1183/13993003.00198-2017

3. Castaldi PJ, DeMeo DL, Kent DM, et al. Development of predictive models for airflow obstruction in alpha-1 antitrypsin deficiency. Am J Epidemiol. 2009;170(8):1005-1013.

doi: https://doi.org/10.1093/aje/kwp216

4. Bernspang E, Sveger T, Piitulainen E. Respiratory symptoms and lung function in 30-year-old individuals with alpha-1 antitrypsin deficiency. Respir Med. 2007;101(9):1971-1976. doi: https://doi.org/10.1016/j.rmed.2007.04.003

5. Wilk JB, Djousse L, Arnett DK, et al. Evidence for major genes influencing pulmonary function in the NHLBI family heart study. Genet Epidemiol. 2000;19(1):81-94. doi: https://doi.org/ 10.1002/1098-2272(200007)19:1<81::AID-GEPI6>3.0.CO;2-8

6. Palmer LJ, Knuiman MW, Divitini ML, et al. Familial aggregation and heritability of adult lung function: results from the Busselton Health Study. Eur Respir J. 2001;17(4):696-702. doi: https://doi.org/10.1183/09031936.01.17406960

7. Silverman EK, Mosley JD, Palmer LJ, et al. Genome-wide linkage analysis of severe, early-onset chronic obstructive pulmonary disease: airflow obstruction and chronic bronchitis phenotypes. Hum Mol Genet. 2002;11(6):623-632. doi: https://doi.org/10.1093/hmg/11.6.623

8. Ingebrigtsen T, Thomsen SF, Vestbo J, et al. Genetic influences on chronic obstructive pulmonary disease - a twin study. Respir Med. 2010;104(12):1890-1895.

doi: https://doi.org/10.1016/j.rmed.2010.05.004

9. Hukkinen M, Kaprio J, Broms U, et al. Heritability of lung function: a twin study among never-smoking elderly women. Twin Res Hum Genet. 2011;14(5):401-407. doi: https://doi.org/10.1375/twin.14.5.401

10. Klimentidis YC, Vazquez AI, de Los Campos G, et al. Heritability of pulmonary function estimated from pedigree and wholegenome markers. Front Genet. 2013;4:174.

doi: https://doi.org/10.3389/fgene.2013.00174

11. Zhou JJ, Cho MH, Castaldi PJ, Hersh CP, Silverman EK, Laird NM. Heritability of chronic obstructive pulmonary disease and related phenotypes in smokers. Am J Respir Crit Care Med. 2013;188(8):941-947.

doi: https://doi.org/10.1164/rccm.201302-02630C
12. Vanscoy LL, Blackman SM, Collaco JM, et al. Heritability of lung disease severity in cystic fibrosis. Am J Respir Crit Care Med. 2007; 175(10): 1036-1043.

doi: https://doi.org/10.1164/rccm.200608-1164OC

13. Silverman EK, Province MA, Rao DC, Pierce JA, Campbell EJ. A family study of the variability of pulmonary function in alpha 1-antitrypsin deficiency. Quantitative phenotypes. Am Rev Respir Dis. 1990;142(5):1015-1021. doi: https://doi.org/10.1164/ajrccm/142.5.1015

14. DeMeo DL, Sandhaus RA, Barker AF, et al. Determinants of airflow obstruction in severe alpha-1-antitrypsin deficiency. Thorax. 2007;62(9):806-813. doi: https://doi.org/10.1136/thx.2006.075846

15. DeMeo DL, Campbell EJ, Brantly ML, et al. Heritability of lung function in severe alpha-1 antitrypsin deficiency. Hum Hered. 2009;67(1):38-45. doi: https://doi.org/10.1159/000164397

16. Lusis AJ. Genetic factors affecting blood lipoproteins: the candidate gene approach. J Lipid Res.1988;29(4):397-429. doi: https://doi.org/10.5924/abgri1983.1988.29

17. Kwon JM, Goate AM. The candidate gene approach. Alcohol Res Health. 2000;24(3):164-168.

18. Moncada S, Palmer RM, Higgs EA. Nitric oxide: physiology, pathophysiology, and pharmacology. Pharmacol Rev. 1991;43(2):109-142.

19. Barnes PJ, Belvisi MG. Nitric oxide and lung disease. Thorax. 1993;48(10):1034-1043.

doi: https://doi.org/10.1136/thx.48.10.1034

20. Novoradovsky A, Brantly ML, Waclawiw MA, et al. Endothelial nitric oxide synthase as a potential susceptibility gene in the pathogenesis of emphysema in alpha1-antitrypsin deficiency. Am J Respir Cell Mol Biol. 1999;20(3):441-447. doi: https://doi.org/10.1165/ajrcmb.20.3.3144

21. Terrier P, Townsend AJ, Coindre JM, Triche TJ, Cowan KH. An immunohistochemical study of pi class glutathione S-transferase expression in normal human tissue. Am J Pathol. 1990;137(4):845-853.

22. Ishii T, Matsuse T, Teramoto S, et al. Glutathione S-transferase P1 (GSTP1) polymorphism in patients with chronic obstructive pulmonary disease. Thorax. 1999;54(8):693-696. doi: https://doi.org/10.1136/thx.54.8.693

23. Rodriguez F, de la Roza C, Jardi R, Schaper M, Vidal R, Miravitlles M. Glutathione S-transferase P1 and lung function in patients with alpha 1-antitrypsin deficiency and COPD. Chest. 2005; 127(5):1537-1543.

doi: https://doi.org/10.1378/chest.127.5.1537 
24. DeMeo DL, Campbell EJ, Barker AF, et al. IL10 polymorphisms are associated with airflow obstruction in severe alpha1antitrypsin deficiency. Am J Respir Cell Mol Biol. 2008;38(1):114120. doi: https://doi.org/10.1165/rcmb.2007-0107OC

25. Hersh CP, Demeo DL, Lange C, et al. Attempted replication of reported chronic obstructive pulmonary disease candidate gene associations. Am J Respir Cell Mol Biol. 2005;33(1):71-78. doi: https://doi.org/10.1165/rcmb.2005-0073OC

26. Wood AM, Simmonds MJ, Bayley DL, Newby PR, Gough SC, Stockley RA. The TNFalpha gene relates to clinical phenotype in alpha-1-antitrypsin deficiency. Respir Res. 2008;9:52. doi: https://doi.org/10.1186/1465-9921-9-52

27. Lander E, Kruglyak L. Genetic dissection of complex traits: guidelines for interpreting and reporting linkage results. Nat Genet. 1995;11(3):241-247. doi: https://doi.org/10.1038/ng1195-241

28. Lander ES, Schork NJ. Genetic dissection of complex traits. Science. 1994:265(5181):2037-2048.

doi: https://doi.org/10.1126/science.8091226

29. Khoury MJ, Yang Q. The future of genetic studies of complex human diseases: an epidemiologic perspective. Epidemiology. 1998;9(3):350-354.

doi: https://doi.org/10.1097/00001648-199805000-00023

30. Lin JR, Cai Y, Zhang Q, Zhang W, Nogales-Cadenas R, Zhang ZD. Integrated post-GWAS analysis sheds new light on the disease mechanisms of schizophrenia. Genetics. 2016;204(4):1587-1600. doi: https://doi.org/10.1534/genetics.116.187195

31. Hirschhorn JN, Lohmueller K, Byrne E, Hirschhorn K. A comprehensive review of genetic association studies. Genet Med. 2002;4(2):45-61.

doi: https://doi.org/10.1097/00125817-200203000-00002

32. Siontis KC, Patsopoulos NA, Ioannidis JP. Replication of past candidate loci for common diseases and phenotypes in 100 genome-wide association studies. Eur J Hum Genet. 2010;18(7):832-837. doi: https://doi.org/10.1038/ejhg.2010.26

33. Ioannidis JP, Tarone R, McLaughlin JK. The false-positive to false-negative ratio in epidemiologic studies. Epidemiology. 2011;22(4):450-456.

doi: https://doi.org/10.1097/EDE.0b013e31821b506e

34. Kraft P, Zeggini E, Ioannidis JP. Replication in genome-wide association studies. Stat Sci. 2009;24(4):561-573. doi: https://doi.org/10.1214/09-STS290

35. Marigorta UM, Rodriguez JA, Gibson G, Navarro A. Replicability and prediction: lessons and challenges from GWAS. Trends Genet. 2018;34(7):504-517.

doi: https://doi.org/10.1016/j.tig.2018.03.005
36. Hobbs BD, de Jong K, Lamontagne M, et al. Genetic loci associated with chronic obstructive pulmonary disease overlap with loci for lung function and pulmonary fibrosis. Nat Genet. 2017;49(3):426-432. doi: https://doi.org/10.1038/ng.3752

37. Wain LV, Shrine N, Artigas MS, et al. Genome-wide association analyses for lung function and chronic obstructive pulmonary disease identify new loci and potential druggable targets. Nat Genet. 2017;49(3):416-425. doi: https://doi.org/10.1038/ng.3787

38. Sakornsakolpat P, Prokopenko D, Lamontagne M, et al; SpiroMeta Consortium, International COPD Genetics Consortium. Genetic landscape of chronic obstructive pulmonary disease identifies heterogeneous cell-type and phenotype associations. Nat Genet. 2019;51(3):494-505.

doi: https://doi.org/10.1038/s41588-018-0342-2

39. Shrine N, Guyatt AL, Erzurumluoglu AM, et al. New genetic signals for lung function highlight pathways and chronic obstructive pulmonary disease associations across multiple ancestries. Nat Genet. 2019;51(3):481-493. doi: https://doi.org/10.1038/s41588-018-0321-7

40. Kim WJ, Wood AM, Barker AF, et al. Association of IREB2 and CHRNA3 polymorphisms with airflow obstruction in severe alpha-1 antitrypsin deficiency. Respir Res. 2012;13:16. doi: https://doi.org/10.1186/1465-9921-13-16

41. Pillai SG, Ge D, Zhu G, et al. A genome-wide association study in chronic obstructive pulmonary disease (COPD): identification of two major susceptibility loci. PLoS Genet. 2009;5(3):e1000421. doi: https://doi.org/10.1371/journal.pgen.1000421

42. Visscher PM, Wray NR, Zhang Q, et al. 10 Years of GWAS discovery: biology, function, and translation. Am J Hum Genet. 2017;101(1):5-22.

doi: https://doi.org/10.1016/j.ajhg.2017.06.005

43. Wright FA, Strug LJ, Doshi VK, et al. Genome-wide association and linkage identify modifier loci of lung disease severity in cystic fibrosis at 11p13 and 20q13.2. Nat Genet. 2011;43(6):539546. doi: https://doi.org/10.1038/ng.838

44. Corvol H, Blackman SM, Boelle PY, et al. Genome-wide association meta-analysis identifies five modifier loci of lung disease severity in cystic fibrosis. Nat Comm. 2015;6:8382. doi: https://doi.org/10.1038/ncomms9382

45. Rigobello C, Baraldo S, Tine M, et al. Exome sequencing reveals immune genes as susceptibility modifiers in individuals with alpha-1 antitrypsin deficiency. Sci Rep. 2019;9(1):13088. doi: https://doi.org/10.1038/s41598-019-49409-1

46. Gamazon ER, Wheeler HE, Shah KP, et al. A gene-based association method for mapping traits using reference transcriptome data. Nat Genet. 2015;47(9):1091-1098. doi: https://doi.org/10.1038/ng.3367 
47. Lamontagne M, Couture C, Postma DS, et al. Refining susceptibility loci of chronic obstructive pulmonary disease with lung eqtls. PLoS One. 2013;8(7):e70220.

doi: https://doi.org/10.1371/journal.pone.0070220

48. Castaldi PJ, Cho MH, Zhou X, et al. Genetic control of gene expression at novel and established chronic obstructive pulmonary disease loci. Hum Mol Genet. 2015;24(4):1200-1210. doi: https://doi.org/10.1093/hmg/ddu525

49. Sun W, Kechris K, Jacobson S, et al; Group SR, Investigators CO. Common genetic polymorphisms influence blood biomarker measurements in COPD. PLoS Genet. 2016;12(8):e1006011. doi: https://doi.org/10.1371/journal.pgen.1006011

50. Aschard H, Tobin MD, Hancock DB, et al. Evidence for largescale gene-by-smoking interaction effects on pulmonary function. Int J Epidemiol. 2017;46(3):894-904. doi: https://doi.org/10.1093/ije/dyw318

51. Oelsner EC, Ortega VE, Smith BM, et al. A genetic risk score associated with COPD susceptibility and lung structure on computed tomography. Am J Respir Crit Care Med. 2019;200(6). doi: https://doi.org/10.1164/rccm.201812-2355OC 